\title{
Erratum: Debons et al. Magnetic Field Alignment, a Perspective in the Engineering of Collagen-Silica Composite Biomaterials. Biomolecules 2021, 11, 749
}

\author{
Nicolas Debons ${ }^{1}$, Kenta Matsumoto ${ }^{2}$, Noriyuki Hirota ${ }^{3}$, Thibaud Coradin ${ }^{1}$ (D), Toshiyuki Ikoma ${ }^{2}$ \\ and Carole Aimé 1,4,*(D)
}

1 Laboratoire de Chimie de la Matière Condensée de Paris (LCMCP), Sorbonne Université, CNRS, 75005 Paris, France; debons.nicolas@hotmail.fr (N.D.); thibaud.coradin@sorbonne-universite.fr (T.C.)

2 Tokyo Institute of Technology, School of Materials and Chemical Technology, Department of Materials Science and Engineering, Ookayama 2-12-1, Meguro-ku, Tokyo 152-8550, Japan; matsumoto.k.be@m.titech.ac.jp (K.M.); tikoma@ceram.titech.ac.jp (T.I.)

3 National Institute for Materials Science, Fine Particles Engineering Group, 3-13 Sakura, Tuskuba 305-0003, Japan; hirota.noriyuki@nims.go.jp

4 Ecole Normale Supérieure, CNRS-ENS-SU UMR 8640, 24 rue Lhomond, 75005 Paris, France

* Correspondence: carole.aime@ens.psl.eu; Tel.: +33-144-323264

check for updates

Citation: Debons, N.; Matsumoto, K.; Hirota, N.; Coradin, T.; Ikoma, T.; Aimé, C. Erratum: Debons et al. Magnetic Field Alignment, a Perspective in the Engineering of Collagen-Silica Composite Biomaterials. Biomolecules 2021, 11, 749. Biomolecules 2021, 11, 1117. https://doi.org/10.3390/ biom 11081117

Received: 31 May 2021 Accepted: 21 June 2021 Published: 29 July 2021

Publisher's Note: MDPI stays neutral with regard to jurisdictional claims in published maps and institutional affiliations.

Copyright: (c) 2021 by the authors. Licensee MDPI, Basel, Switzerland. This article is an open access article distributed under the terms and conditions of the Creative Commons Attribution (CC BY) license (https:/ / creativecommons.org/licenses/by/ $4.0 /)$.
In the original article, there was a mistake published in Figure 2. The figure was published twice in the original published version [1]. The corrected Figure 2 is shown below. We apologize for any inconvenience caused, and state that the scientific conclusions are unaffected. The original article has been updated.

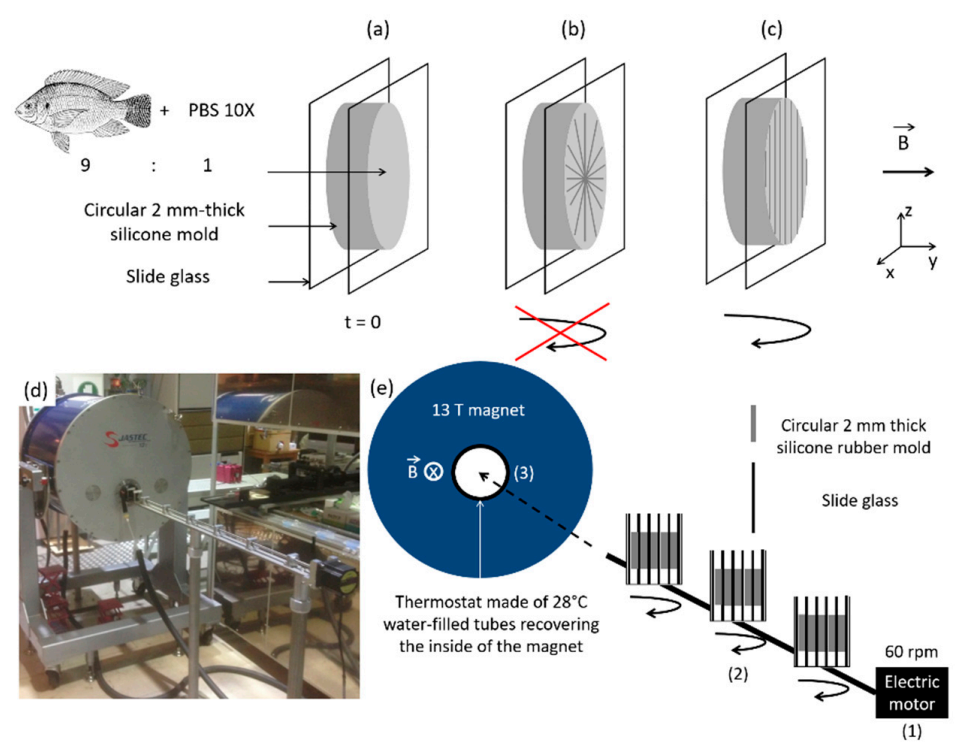

Figure 2. (a) Magnetic field application in a collagen gel. (b) Under a high magnetic field along y axis and without rotation, collagen fibers perpendicularly align against magnetic field (xz plan). (c) Upon rotation, only fibrils along the axis of rotation ( $\mathrm{z}$ axis) remain. (d) Photo of the set-up, and (e) scheme of the essential characteristics: electric motor for stirring samples, magnetic field and thermostat.

\section{Reference}

1. Debons, N.; Matsumoto, K.; Hirota, N.; Coradin, T.; Ikoma, T.; Aimé, C. Magnetic Field Alignment, a Perspective in the Engineering of Collagen-Silica Composite Biomaterials. Biomolecules 2021, 11, 749. [CrossRef] [PubMed] 